\title{
ETL
}

International Conference on Research in Education, Teaching and Learning

Paris, France| November 2-4, 2018

\section{The Importance of Project Based Learning (PBL) Within Modern Teaching Methods, ESPRIT as A Case Study}

\author{
Manel Chaouachi
}

\begin{abstract}
Choosing to write about "The importance of Project Based Learning (PBL) within modern teaching methods, ESPRIT as a case study" is premised upon the belief that adopting new teaching approaches and methods is highly essential to guarantee successful learning outcomes. Hence, my poster presentation has opted for this particular topic in an attempt to demonstrate the several advantages of PBL as an interactive and dynamic modern approach while identifying and discussing my experience with Tunisian engineering students at ESPRIT. Having been adopted at ESPRIT for several years, the PBL initiative is one of the reforming engineering education compared to the traditional way of teaching. This poster is intended to provide a starting point for anyone who wishes to learn about the PBL model. In these respects, PBL will be defined through my presentation as an original learning process to help students achieve the maximum of learning outcomes. Overall, my work will revolve around innovative ideas, strategies and projects that I have experienced with my students to reach an effective project-based learning. As a conclusion, some observations on common lessons learned and teamwork projects will be further discussed.
\end{abstract}

Keywords: Engineering Studies, Innovation, Project-Based Learning 
